\title{
En busca del enemigo oculto: intelectuales y revistas antinazis en el Uruguay de la Segunda Guerra Mundial ${ }^{*}$
}

\author{
Looking for the Hidden Enemy: Intellectuals and Anti-Nazi Magazines \\ in Uruguay During the Second World War
}

Mariana Moraes Medina

Universidad Adolfo Ibáñez/ANID, Chile, mmoraes.medina@gmail.com

ORCID: 0000-0003-2826-5580

\section{Date of reception: \\ $13 / 12 / 2019$}

Date of acceptance: $18 / 07 / 2020$

Citation: Moraes Medina, Mariana, "En busca del enemigo oculto: intelectuales y revistas antinazis en el Uruguay de la Segunda Guerra Mundial", Revista Letral, n. ${ }^{\circ}$ 24, 2020, pp. 1-21. ISSN 1989-3302.

DOI:

http://dx.doi.org/10.30827/R L.voi24.11690

Funding data: The publication of this article has not received any public or private finance.

License: This content is under a Creative Commons Attribution-NonCommercial 3.o Unported license.

\section{(). $(1) \Theta$}

\section{RESUMEN}

En este artículo se examina un conjunto de revistas uruguayas que iniciaron su publicación como respuesta local a los peligros del avance del nacionalsocialismo alemán durante la Segunda Guerra. Partiendo de la teoría del complot como ficción mundial vigente en la época (Louis 2007) y de los debates del contexto político nacional, se analiza la representación y los usos de la amenaza nazi que exhiben estas publicaciones. El trabajo pone en evidencia cómo las revistas colaboraron con la hibridación del imaginario del nazismo y con la difusión de una narrativa del temor y la sospecha. El estudio de estas publicaciones "antinazis" permite, asimismo, echar luces sobre trayectorias intelectuales individuales y esbozar la continuidad de una red de escritores uruguayos antifascistas forjada en la década del treinta bajo la experiencia de la dictadura de Terra y de la adhesión a la causa de la España republicana.

Palabras clave: revistas; intelectuales; nazismo; Segunda Guerra Mundial; Uruguay.

\begin{abstract}
This article examines a set of Uruguayan magazines first published as a local response to the dangers of German National Socialist progress during the Second World War. Starting from plot theory as a world fiction in force at the time (Louis 2007) and the debates of the national political context, it analyzes the representation and uses of the Nazi threat that these publications exhibit. The work highlights the ways in which these magazines collaborated with the hybridization of the imaginary of Nazism and the dissemination of a narrative of fear and suspicion. Moreover, the study of these "anti-Nazi" publications allows us to shed light on individual intellectual paths and sketch the continuity of a network of Uruguayan anti-fascist writers forged during the 1930s under the experience of Terra's dictatorship and the adherence to the cause of Republican Spain.
\end{abstract}

Keywords: magazines; intellectuals; Nazism; Second World War; Uruguay.

\footnotetext{
* Este trabajo es resultado del proyecto Fondecyt Postdoctoral n ${ }^{0}$ 3190376: "Escritores del Cono Sur ante la Segunda Guerra Mundial: redes, cooperación intelectual y representaciones a través de revistas culturales y archivos (1939-1947)”, del que su autora es Investigadora Responsable.
} 


\section{De la guerra distante al enemigo interno}

Para la sociedad uruguaya, la Segunda Guerra Mundial representó no sólo un asunto de gran interés informativo, sino también un verdadero acicate de pasiones. La raíz de esa fuerte implicación en el avance de la contienda distante podría tal vez ubicarse en la percepción, compartida por muchos latinoamericanos, de ser miembros de un orden político mundial y de una comunidad de cultura, afectos y lealtades que se extendería más allá de las fronteras de la nación y del continente. Enfrentado a la exigencia de tomar partido, de acuerdo con las "políticas de la amistad" que han ordenado las prácticas de la hostilidad y la guerra en Occidente (Derrida 1998), Uruguay se integró al orbe de colaboradores de los Aliados. Una vez más, el peso de la devoción cultural hacia Francia y de la dependencia comercial con Inglaterra (sumados a la creciente incidencia hemisférica de los Estados Unidos) hacía inviable cualquier otro posicionamiento. Los efectos de esta identificación pueden observarse en las numerosas muestras de solidaridad con los pueblos afectados por los avances del Eje, pero también en la transposición, al medio local, de la narrativa del temor a una invasión nazi. Este recelo fue creciendo alimentado por la idea de la existencia de una conspiración que buscaría extender los dominios del Reich más allá de Europa, a través del apoyo de una "quinta columna", una suerte de organización transnacional y secreta que desarrollaría tareas de espionaje mediante los alemanes que residían en el extranjero. De este modo, a pesar de la distancia respecto de la zona del enfrentamiento armado, muchos uruguayos fueron proclives a sufrir por las derrotas y vejámenes impuestos a sus prójimos transatlánticos y también a hacer propias las ficciones que configuraban enemigos y temores. Al fin y al cabo, como ha propuesto Umberto Eco: "para hacer la guerra se necesita a un enemigo con quien luchar, el carácter de la guerra se corresponde con lo ineluctable de la elección y construcción del enemigo" (35).

Las huellas de ese temor al "quintacolumnismo" (intercambiable, en su esquema narrativo, con la teoría del “enemigo interno") y el catálogo de imágenes que este fue suscitando impregnan la cultura impresa de la época y, en particular, las páginas de revistas y periódicos locales. Conectados al sistema de la prensa mundial, estos se presentan como una fuente destacada para el estudio del plegamiento mostrado por la periferia en torno a la imagen exógena del enemigo. Con base en estos aspectos y desde el enfoque de las transferencias culturales ${ }^{1}$, proponemos, como objetivo central de

${ }^{1}$ Espagne (1999) ha definido las transferencias culturales como el intercambio de ideas, conceptos, símbolos o cualquier artefacto cultural entre distintas 
este trabajo, la revisión de la figuración y los usos de la amenaza nazi en Mundial, Boletín Antinazi, Acción Antinazi y Mundo Libre, revistas representativas de diversos momentos y sectores del movimiento antifascista uruguayo. La construcción de la muestra pretende poner en valor una constelación de publicaciones desatendida hasta el día de hoy pero sumamente valiosa en sus potencialidades documentales, tanto para el estudio de la recepción cultural de la Segunda Guerra Mundial en América Latina, como para la apertura de nuevas perspectivas sobre trayectorias intelectuales individuales.

\section{Pangermanismo y cultura antifascista en el Uruguay de los años treinta}

Entre 1933 y 1938, la tradición demócrata uruguaya, acorralada por el desastre económico y la oposición al reformismo batllista, conoció el despliegue de un paréntesis autoritario a raíz del autogolpe de estado de marzo de 1933, organizado por el presidente Gabriel Terra y apoyado por sectores conservadores ${ }^{2}$. El golpe selló la crisis de la democracia liberal y favoreció un acercamiento político, militar y comercial con los regímenes de Mussolini y de Hitler3. Según ha propuesto la historiadora María Camou, la Alemania nazi, en particular, vio fortalecida su imagen e influencia en Uruguay a través de la inyección de capitales, la colaboración con el planeamiento de obras estatales, el aumento de los acuerdos de intercambios comerciales y la intensificación de la propaganda del nacional-socialismo en las colonias alemanas:

Los nazis uruguayos dispusieron para sus actividades de absoluta libertad de movimientos, y realizaron así numerosos actos públicos, encuentros de ex combatientes, campamentos

áreas culturales - por lo común, nacionales-. El teórico contempla que la importación de estos elementos de un espacio cultural a otro resulta en un proceso creativo de "mestizaje" o "hibridación".

${ }^{2}$ Militante del partido Colorado, Terra se distanció del sector duro del batllismo, que pasó, a partir de entonces, a conformar la oposición. El golpe recibió el apoyo de los sectores conservadores del espectro político uruguayo, entre ellos el del dirigente del sector mayoritario del partido Blanco, Luis Alberto de Herrera (Alpini 9-15). El gobierno de Terra tuvo continuidad en la presidencia de su colaborador Alfredo Baldomir (1938-1942).

${ }^{3}$ Cabe apuntar que no sólo se trató de la germanofilia y la atracción hacia el movimiento liderado por Mussolini, también el falangismo sedujo a la derecha nacional. De hecho, varios políticos e intelectuales uruguayos emprendieron el viaje a la utopía fascista, entusiasmados por las "nuevas" Italia, España y Alemania. Así, Gabriel Terra visitó Italia, invitado por el gobierno de Mussolini en 1938 (Rodríguez Aycaguer 259-261); Luis Alberto de Herrera, la España franquista en 1937 (Alpini 23); y el periodista y escritor Adolfo Agorio, la Alemania del Tercer Reich en 1935 (Camou 76). 
de entrenamientos, marchas, etc. Contaron con su propia emisora radial que transmitía las marchas e himnos del partido, discurso de Hitler y Goebbels, etc., y distribuían numerosas publicaciones, editadas en Alemania en español por el Iberoamerikanisches Institut Hamburg, entre sus simpatizantes. No escaparían tampoco al proselitismo los alumnos de los numerosos colegios alemanes (Camou 77).

El papel de las publicaciones periódicas para la propaganda nazi fue fundamental. Circulaban por entonces el periódico Deustche Wacht, el que se definía como órgano de lucha del movimiento nacional-socialista en Uruguay; el Deustche La Plata Zeitung, que ingresaba desde la orilla vecina, además de las publicaciones filofascistas editadas por grupos de la derecha radical nacional, como Corporaciones, El Debate, El Diario, Fragua, Patria, entre otras, que coincidían con aquellas en la difusión de un discurso racista y antisemita.

Las no disimuladas simpatías por el pensamiento nacionalista-fascista y el estrechamiento de las relaciones con la Alemania nazi fueron motivo de preocupación tanto para los demócratas uruguayos como para los gobiernos de Inglaterra y Estados Unidos. El peligro que representaba Alemania para la conservación de la hegemonía mercantil de estos últimos provocó que, previo al inicio del enfrentamiento armado, Latinoamérica se convirtiera en el mapa de una guerra ideológica y de capitales. La ofensiva más determinante para intentar frenar las conquistas del pangermanismo en la región se consolidó en torno a la política de la Buena Vecindad, la que procuró derrotar a Alemania comercialmente y combatir la nazificación del continente (Friedman 2013), entre otras campañas que apuntaban al logro del dominio hemisférico.

En esa cruzada el papel de la propaganda a través de los medios de comunicación y de la acción de los intelectuales fue crucial. En el caso de estos últimos, el panamericanismo supo aprovechar los sucesos de España para establecer alianzas con los sectores antifranquistas, comprendiendo que la raíz hispánica y la gran adhesión de la intelectualidad latinoamericana a la causa de la República concederían sustento y unidad al movimiento antifascista y antinazi (Degiovanni 2019) 4 . Esto se comprueba en el campo cultural uruguayo, donde la implicación con la causa de

4 En Vernacular Latin Americanisms: War, the Market, and the Making of a Discipline (2019), Fernando Degiovanni ha estudiado un asunto poco abordado y de sumo interés: el vínculo entre la "España peregrina" y la intervención estadounidense en América Latina entre los años treinta y la Segunda Guerra Mundial. En el trabajo se demuestra que las funciones asumidas por los intelectuales latinoamericanos antifranquistas y los españoles exiliados en Estados Unidos en el seno de la institución panamericana implicaban el desarrollo de labores de propaganda y, en ocasiones, también de espionaje. 
la República, el fusilamiento de García Lorca y la recepción de exiliados españoles fortaleció la identificación con la consigna "demócrata y antifascista" y determinó un incremento del rechazo a los discursos antisemitas y cercanos al nacionalismo fascista normalizados bajo el gobierno de Terra 5 .

Uno de los grupos más representativos de esa configuración fue la Asociación de Intelectuales, Artistas y Periodistas (A.I.A.P.E.) 6 , un colectivo que reunía todos los componentes de la cultura antifascista que en torno a los años 1939-1940 se volvería hegemónica en el país, definiéndose demócrata, antifranquista, aliadófila, panamericana y antinazi. En ella participaban intelectuales de diversas banderas partidarias -socialistas, batllistas, blancos independientes y comunistas-, como Emilio Frugoni, Paulina y Luisa Luisi, Emilio Oribe, Juvenal Ortiz Saralegui, Carlos Sábat Ercasty, Enrique Amorim, Giselda Zani, Esther de Cáceres, Roberto Ibáñez, Francisco Espínola, entre otros. Eran, en su mayoría, escritores vinculados a la Generación del Centenario, con una fuerte identificación con el reformismo batllista y el humanismo liberal7. Su labor a favor de los aliados fue el motor para la

5 Marcha, una de las publicaciones más relevantes de estos años, plasmaba en su línea editorial -ya desde el primer número- esa militancia: "El fascismo, asesino y bestial, se cierne sobre toda la humanidad y amenaza ahogarla en la noche más espantosa. Vivimos días decisivos. En la medida de nuestras posibilidades, lo decimos sin ambages, MARCHA será una trinchera contra el fascismo. Desde ella, al entrar en el combate, enviamos el cordial saludo a todos los luchadores antifascistas" (23 de junio de 1939, 9). La portada de ese número ya advertía acerca de la infiltración nazi en Uruguay (que replicaría en Marcha 52, 21 de junio de 1940).

${ }^{6}$ La institución editaba el Boletín por la defensa de la cultura. El número 25, correspondiente a mayo de 1939, resulta muy ilustrativo de la convergencia de posicionamientos que comentamos. A raíz de la quema pública de libros realizada por los nacionales frente a la Universidad de Madrid el 30 de abril de ese año, la A.I.A.P.E. organizó un acto en recuerdo de la "Semana del libro quemado" (Alemania, mayo de 1933). El establecimiento de este diálogo a partir de los "autos de fe" llevados adelante por los regímenes totalitarios constituye toda una operación de combate del nazismo, el que por ese entonces era ya una amenaza de entidad para el orden mundial. La revista reseñaba las actividades llevadas a cabo por la Asociación en esa oportunidad, entre las que figuran la lectura de fragmentos de libros quemados y el intercambio con alemanes no nazis. El número incluye un texto en homenaje a Heinrich Heine (poeta que por su condición de judeo-alemán se transformó en un símbolo de la resistencia antinazi en las revistas de la época), publicidad del Banco Israelita del Uruguay y del libro El infierno nazi que recogía las entrevistas realizadas por el escritor Francisco "Paco" Espínola a emigrados de la Alemania de Hitler.

7 En 1942, el presidente Baldomir cede a la presión internacional y de la oposición, y disuelve el Parlamento, dando lugar a un Consejo de Estado y la convocatoria a elecciones. A partir de entonces la postura oficial del gobierno uruguayo se volverá abiertamente pro aliada. En ese marco se reorganizó la Comisión Nacional de Cooperación Intelectual, que había dejado de funcionar 
escritura de ensayos, artículos y obras de creación, la elaboración de traducciones, edición de números monográficos en revistas, manifiestos y fundación de agrupaciones de ayuda, los que conforman un rico archivo de la cooperación intelectual transatlántica durante el desastre ${ }^{8}$. La ocupación de París por las fuerzas de Hitler, a finales de junio de 1940, los conmocionó profundamente y terminó de definirles el nombre del enemigo compartido pero oculto.

\section{Ficciones mundiales, teoría del complot y espionaje}

Valiéndose de audiciones radiales primero y luego del libro Nazis en Uruguay (1940), el intelectual Hugo Fernández Artucio denunció las operaciones de los agentes de Hitler en territorio nacional. Según el autor, se trataba de un peligro inminente que podría instalar en el país - parafaseando el poema "MadridOtoño" de Rafael Alberti- "el cuadro de la angustia nocturna, de rostros lívidos con ojos desvelados; con el dolor de las capitales maduras para los bombardeos, con avenidas de escombros y barrios en ruinas" (Fernández Artucio 21). A raíz de la enorme credibilidad con la que contaba el denunciante y su relato, el Parlamento creó la Comisión de Investigaciones de Actividades Antinacionales (espejo de la comisión norteamericana), la que se encargó de indagar en la infiltración del nazismo 9 . Atendiendo a esto, fueron investigados colegios, clubes, bancos, empresas, instituciones y particulares vinculados con la colonia alemana e italiana. La labor de esta comisión concitó toda la atención de la prensa y la ciudadanía pues llevó a juicio a numerosos ciudadanos extranjeros y nacionales acusados de connivencia con el Eje y de fraguar un plan para atentar contra la soberanía uruguaya (conocido como "plan Fürhmann"). Los resultados de esa pesquisa se publicaron como anexo en ediciones posteriores de Nazis en Uruguay y en el libro de Brena e Iturbide (dos de los investigadores que conformaban el mencionado organismo) Alta traición: los nazis en el Uruguay (1941).

Mientras tanto, en el centro del debate político nacional se

en 1937 y cuya labor de defensa de la cultura y entendimiento entre los pueblos era fomentada por la Sociedad de Naciones.

8 Un aspecto que ameritaría otro desarrollo es el hecho de que buena parte de estos escritores accedieran a cargos diplomáticos, viajes de intercambio, nombramientos en instituciones culturales - entre otras formas de consagraciónsobre el final de la guerra.

9 El tenor moral de la figura de Fernández Artucio en el campo intelectual uruguayo estuvo dado, primero, por su militancia en contra de Terra como miembro del Partido Socialista Uruguayo, acción por la que enfrentó juicio y prisión y, en segundo lugar, por su participación en la Guerra Civil Española, como voluntario de las Brigadas Internacionales (Tricánico 121). 
discutía la neutralidad y la beligerancia en relación con la contienda mundial y, no muy distante de ello, la sanción de medidas de defensa que incluían la instalación de bases militares norteamericanas en territorio uruguayo y la instrucción militar obligatoria (Cerrano y López D’Alessandro 2018). En torno a estos temas se enfrentaban las posturas aislacionistas (entre las que destacaba el sector del Partido Nacional, liderado por Luis Alberto de Herrera), que proponían mirar por los intereses del país y la región, con las universalistas o internacionalistas (donde se daban cita todos los sectores del progresismo liberal y de izquierda), que apoyaban la intervención en el conflicto extranjero invocando la lealtad a valores demócratas y humanitarios. Como es de suponer, las investigaciones de actividades pro nazis dialogaban con esos debates. De hecho, la teoría del complot se adormecía o revivía en los medios de prensa en función de los vaivenes de la política regional e internacional.

En líneas generales, podrían delimitarse dos grandes momentos en la recepción de la teoría del complot nazi en Uruguay. La primera es la referida anteriormente, el desenmascaramiento de los espías nazis de 1940, mientras que la segunda se materializó en torno a 1943-1944, coincidiendo con la consolidación del gobierno militar de Farrell y Perón y el proceso de ascenso de este último. El hecho alimentó nuevamente el temor uruguayo a la invasión, pero esta vez la amenaza se representaba más cercana e integraba el componente criollo, pues se especulaba con una alianza entre el general Perón, Hitler y Franco, la que facilitaría la migración del Tercer Reich a Sudamérica después de terminada la guerra. En respuesta a esto, las medidas antinazis fueron extremadas, al punto de que la prensa publicó "listas negras" elaboradas por el Servicio de Inteligencia de Estados Unidos, en las que se detallaban los nombres de los ciudadanos uruguayos (en su mayoría con apellidos italianos y alemanes) sospechosos de colaboración con el $\mathrm{Eje}^{10}$.

Hasta el momento, no se cuenta con la completa certeza de que el "plan secreto" para dominar Uruguay haya existido verdaderamente, a pesar de que sí se han documentado pruebas de las operaciones de propaganda y del espionaje alemán en la región del Río de la Plata (Camou 1986; Tricánico 2012; Mutti 2015). Más aun, la autenticidad de la "teoría del complot nazi" como tal ha sido puesta en tela de juicio en pesquisas que la catalogan como un invento de la inteligencia británica y el fruto de un "proceso de desinformación circular" llevado adelante por el gobierno de Estados Unidos y la prensa sensacionalista (Friedman 150-154).

Con independencia de su autenticidad o falsedad, no es

10 Ver "La lista negra oficial”, El País, Montevideo, 25 de agosto de 1944. 
posible negarles a los esquemas narrativos derivados de los planes imperiales de Hitler un gran poder de sugestión y efectividad transnacional, en tanto instalaron el miedo y el estado de alerta en la vida de muchas personas en diversas latitudes ${ }^{11}$. Gran parte de la fuerza de esas ficciones podría estar dada, como ha apuntado Annick Louis, por el carácter secreto del complot, es decir, por la idea de la existencia de "un grupo percibido como solidario e internacional, que intenta mantenerse oculto y cuyo objetivo es dominar el mundo" (165) ${ }^{12}$. Precisamente, a la creencia en el ocultamiento de los conspiradores podría atribuirse el incremento de las interpretaciones paranoicas de la realidad y la instalación de una lógica detectivesca en el imaginario social de la época, palpable no sólo en la literatura de ficción, sino también en la prensa y en revistas, pues el relato del complot hitleriano constituyó la mistificación o ficción mundial más relevante en lo que hace a la composición de la literatura mediática de la guerra.

Por otra parte, para Louis, el deseo de descifrar o revelar lo que permanece oculto respondería a una necesidad propia de la racionalidad moderna, preocupada por encontrar un orden detrás del caos que aparenta ser la realidad sin el sustento de las bases metafísicas tradicionales (169). Desde esta perspectiva, la aceptación y atractivo de la teoría del complot nazi resultarían de que esta funcionó como un sistema de desciframiento de la realidad, si bien no fue el único vigente en su momento. Durante la guerra, la difusión del esquema de la conspiración de Hitler convivió con otras ficciones, como la del heroísmo y sacrificio de los imperios británicos y estadounidense, con sus esforzados

${ }^{11} \mathrm{El}$ análisis del miedo (y las emociones en general) en investigaciones inscritas en los campos disciplinares de la historia y la política global es bastante reciente. La obra de Jean Delumeau La peur en Occident (XIVe-XVIIIe Siècles): Une cité assiégée (1978) constituye un antecedente muy provechoso en este sentido. Desde la historia de las mentalidades y manejando un extenso corpus de fuentes literarias, el historiador francés analiza el peso que el miedo (o el sentimiento de inseguridad) ha tenido en el comportamiento de las sociedades. En el campo de las relaciones internacionales, autores como Neta C. Crawford (2000), entre otros, han avanzado en analizar la incidencia que las emociones colectivas poseen en la constitución de comunidades políticas y su implicación en la guerra. Finalmente, en el ámbito de la crítica cultural, es reseñable el trabajo de Antonia Viu (2018), pues propone un valioso acercamiento a la relación entre revistas latinoamericanas, guerra y comunidades de afectos.

${ }^{12}$ Louis señala que, durante la década de 1930, con la afirmación de los planes de dominio imperial de los fascismos, las ficciones conspirativas tuvieron un momento de auge. No obstante, recuerda que los complots fueron diversos y que se sucedieron a partir de la modernidad, culpabilizando a facciones muy variadas (judía, nazi, jesuita, masona o comunista, etc.). En algunos casos, de hecho, una teoría de la conspiración se levantaría en respuesta a otra, como el propio complot nazi, que podría entenderse como respuesta a un complot judío (Louis 161). 
ejércitos, servicios de inteligencia y demás elementos del aparato de contraespionaje, ilusiones también estos de un orden ante una realidad caótica. Siguiendo a Louis, estas "ficciones imperiales" pueden ser leídas, en general, como "ficciones del control" (163166), en el sentido de lo propuesto por Thomas Richards en The Imperial Archive. Knowledge and the Fantasy of Empire (1993). Para el autor, desde la era victoriana, Inglaterra se habría abocado a la producción de relatos que le permitieran mantener la idea de control mundial. Una de las principales estructuras simbólicas a estos efectos se componía de representaciones vinculadas a la recogida de información por parte de instituciones como la Royal Geographical Society, el British Museum o el aparato de seguridad formal del Estado. Las prácticas de vigilancia aseguraban, según ese relato, el conocimiento y dominio del territorio sobre el que el imperio manifestaba tener el control. Este es el origen de ficciones ricas en personajes nómadas -soldados, científicos, espías-, expertos en componer mapas, descifrar lenguas muertas o códigos secretos y que representaban, según Richards, la "supervisión nomádica" del imperio (22).

Avanzada la primera mitad el siglo XX, la productividad de "ficciones imperiales" no menguaría, sino todo lo contrario, crecería con los insumos de la técnica y los medios de comunicación. La vitalidad de este tipo de relatos se evidencia en el desarrollo del cine y la literatura entre las décadas de 1930 y 1940, años sustanciosos para los géneros fantástico y policial, y para el fortalecimiento del thriller. Así, las ficciones "artísticas" expresarían, en cierto modo, la angustia ante las ficciones que conformaban la realidad efectiva y que delineaban un presente de villanía, sospechas (en especial en relación con los extranjeros), enemigos ocultos, espías, sociedades secretas, traición, heroísmo e invasiones inminentes ${ }^{13}$. En Onetti, la atmósfera del hampa, los personajes extranjeros entre los que suelen haber judíos y alemanes; en Borges y Arlt, las sociedades secretas y la violencia contenida; y en Bioy, los espías, entre otros elementos, sumarían algunos ejemplos rioplatenses de la productividad ficcional de las grandes amenazas difundidas por la literatura mediática.

\section{Mundial contra los "bárbaros ocultos"}

La revista Mundial circuló entre abril de 1940 y noviembre de 1957 con una periodicidad mensual. Ya desde el título, el diseño de su logo (ilustración de monumentos emblemáticos de París,

13 Para profundizar en este tema se recomienda el trabajo de Javier de Navascués (2015). Para el autor, el miedo a la invasión se constituyó en un verdadero tópico de la literatura rioplatense a partir de los años cuarenta. 
Londres, Roma y Berlín) y el manifiesto fundacional, expresaba la pretensión de inscribir al país en un orden internacional: "MUNDIAL es la tribuna verbal y el campo de acción de la democracia del mundo en una parte del mundo mismo, aquí, en el Uruguay" (Mundial 1, abril 1940, 3). La extensa e intensa cobertura del desastre europeo que encontramos en sus páginas durante los primeros años la convierte en una revista sobre la guerra (y no, como fue común, una revista cultural con una sección dedicada a la contienda). De hecho, su tono y estética belicistas, unidos a la inclusión de mapas, datos sobre estrategia, armamento y avances tecnológicos expresan un énfasis en la dimensión militar y épica del conflicto, algo por otra parte, bastante exaltado en las publicaciones del momento, junto con el protagonismo concedido al fotoperiodismo, el que, en Mundial, insiste en el toque escabroso, reproduciendo de forma frecuente imágenes tremendistas de bombardeos, heridos y cadáveres.

La firma del redactor responsable es la de "Francisco Espínola, hijo", modo como el escritor "Paco" Espínola (19041973) se identificó hasta la muerte de su padre, en 1948. El papel del escritor al frente de la revista durante su primera época (1940-1943) no ha sido abordado en ninguno de los estudios sobre su trayectoria intelectual hasta el momento ${ }^{14}$ (de hecho, su labor como periodista, colaborador de Mundo uruguayo, Marcha y El País, merecería más atención). Demócrata tenaz, con militancia como blanco independiente, Espínola fue uno de los pocos intelectuales que participó en la revuelta armada contra el gobierno de Terra en 1935, lo que le valió ser encarcelado por el régimen (Maggi 403).

La tarea desarrollada como redactor responsable de una publicación con las características de Mundial revela a un intelectual atento a las causas de su tiempo, perfil universalista que se conjuga con el escritor de las notas de cultura en Marcha y que contrasta con la imagen más extendida que se tiene de Espínola como narrador "nacional", encerrado en el terruño, en una poética localista, de atmósfera y personajes pasadistas en el contexto de una literatura cada vez más volcada hacia lo urbano. $\mathrm{Al}$ poco comentado compromiso con causas internacionales, como la lucha antinazi, se suma la pertenencia del autor a la masonería (también es el caso de Fernández Artucio), un dato no menor para su militancia anti hitleriana si se atiende a que el Führer había ordenado la persecución a las sociedades secretas, entre las que figuraban las logias masónicas, por considerarlas

14 Espínola es un escritor canónico dentro de Uruguay, aunque poco conocido fuera de fronteras. Ha sido reconocido mayormente como cultor de la literatura regionalista "posgauchesca” (Rocca 2002). 
aliadas de los judíos ${ }^{15}$.

Como la mayoría de las publicaciones pro-aliadas del periodo, Mundial presenta la causa franco-británica como la del "imperio moral" (Mundial 1, 1940, 3) y participa del imaginario de demonización de los nazis difundido por la prensa inglesa y estadounidense. La revista busca intervenir en el debate sobre asuntos de defensa nacional con artículos que proponen extremar las medidas de seguridad e insisten en la idea de la infiltración hitlerista como peligro inminente sobre el país:

Las 'quintas columnas' están también en nuestra tierra. El Uruguay debe defenderse de la propaganda totalitaria, debe resguardarse severamente de las organizaciones nazis, calcadas en las peligrosas legiones descubiertas en otros países de América (“Quintas columnas”, Mundial 2, 1940, 3).

Se reitera la advertencia acerca de la existencia de agentes alemanes y uruguayos al servicio de la Gestapo, replicando los resultados de las investigaciones de la Comisión de Investigaciones de Actividades Antinacionales. Así, se publican detalles del complot para una ocupación militar del Uruguay y noticias sobre espías que circulan disfrazados de turistas y mendigos, o el hallazgo de fotografías del litoral uruguayo y de bases aeronáuticas en poder de supuestos agentes de Hitler. Todo ello alimenta un imaginario del espionaje en consonancia con la imagen estereotipada de los nazis que difundió el cine norteamericano: seres siniestros, oscuros, acechantes, sigilosos y dados a la perfidia y la crueldad.

La revista también presenta, por oposición, ejemplos de virtud o heroísmo encarnados por aquellos que condujeron las investigaciones para capturar y desbaratar el complot. Estos personajes son presentados como modelos de patriotas, un tropo que se reitera insistentemente en los textos de la época y que funciona como la contracara de la figura del traidor ${ }^{16}$. Bajo estos términos se difunde la teoría de una conspiración entre extranjeros y nazis criollos, un grupo representativo del "herrerismo nazi-fascista-falangista-nipón" (Mundial 24, 1942).

Queremos que los nazis y nazi criollos, capaces de callar con tanta miserable cobardía, como capaces de obrar con tanta

15 Un perfil biográfico con el título "Hermano Francisco Espínola” en el sitio de la Gran Logia de la Masonería del Uruguay informa que su ingreso a la misma se dio en el año 1928, siguiendo los pasos de su padre, en la Logia Dupla Alianza de la localidad de San José.

${ }^{16}$ Se podría relacionar este imaginario del traidor y del patriota como una ansiedad del momento en el Río de la Plata de los años cuarenta. Si se observa la obra de Borges, por ejemplo, esta textualiza ese conflicto en la dualidad de muchos de sus personajes, como ha trabajado Annick Louis en Borges y el fascismo (2007). 
osada impunidad, tengan la sensación íntima, bien sensible, a flor de piel, dentro de sus almas, que nosotros les decimos y le repetimos, tratando de encontrar sus caras ocultas, tratando de apuñalearles la mente, que repudiamos la obra nefasta de Hitler y, por eso mismo, los nazis y los nazis criollos de este país, deben sentirlo, sufrirlo antes que él, y sentirse humillados y castigados por la solidaridad democrática del Uruguay ("Nuestro repudio", Mundial 2, 1940, 3).

La amenaza, el estado de alerta, se expresa también en los aspectos materiales de la publicación, en especial en el fondo oscuro y el diseño pesado, sombrío. Uno de los casos más reseñables en este sentido es el del número 3, correspondiente a junio de 1940. En este, Mundial propone una ilustración de portada con el contorno del mapa de Uruguay y una mano en forma de garra que se cierne amenazadoramente sobre él. En este número, en especial, se carga contra las publicaciones pro-nazis que circulaban en el medio.

Sabemos que si no reaccionamos contra esa gran prensa mistificadora de las palabras se transforman en la sombra de los actos, que se publica entre nosotros y se vende entre nosotros, especulando con todas las alarmas y con todas las mentiras hasta que llegue la oportunidad en que la quinta columna nos clave el puñal hasta la médula y haga andar, por la avenida 18 de Julio, las horcas rodantes de las calles de Varsovia, caeremos inocentemente en las trampas de estas letras de imprenta, en la red de tinta negra de estas fábulas totalitarias que no tienen otro fin que el de erigir el imperio de un mito contrario a la Humanidad con la destrucción de todos los pueblos, menos uno... (Mundial 3, 1940, 3)

La "red de tinta negra" sobre la que advierte Mundial da cuenta de ese otro gran y decisivo campo de batalla de la guerra: el de la cultura impresa. Como ya adelantamos, el origen y función de las propias revistas antinazis debería buscarse en relación con ese maremágnum de publicaciones y folletos nazifascistas que circulaban en la región, si bien cada vez más de forma clandestina, debido a la fuerte condena social que acarreaban.

De Espínola, se conoce que, tras este servicio al antifascismo a través de la prensa, participó en el Congreso Mundial de los Intelectuales por la Paz en Polonia, en 1948, y luego como delegado ante la UNESCO en 1953. Suele recordarse que sobre el final de su vida se afilió al Partido Comunista. Precisamente en su discurso de ingreso a esta organización, el autor de Raza Ciega repasaba las causas por las que había trabajado desde el frente intelectual, entre las que se encuentra su compromiso antinazi: 
Por Sandino, contra la dictadura del año 33, a favor de la República Española, contra el fascismo y el nazismo posterior, contra el antisemitismo, por la causa aliada en la Segunda Guerra Mundial, contra la invasión de Guatemala, y después, claro está, hasta estos días, en defensa de la Cuba Socialista y del heroico pueblo del Vietnam (Espínola 33).

\section{Boletines antinazis: combatiendo la infiltración nazi en el ámbito burocrático y obrero}

Dos boletines que inician su circulación casi en simultáneo en 1944 permiten, dado su origen institucional, un acercamiento al combate del nazismo en ambientes laborales: el Boletín Antinazi y Acción Antinazi. Ambos se declaran órganos de prensa de comités de ayuda pro-aliada asociados a gremios y sindicatos de trabajadores. En su ideación gráfica y materialización, los boletines guardan una fuerte impronta sindical; de hecho, su austeridad y brevedad los acerca a las hojas sueltas.

La aparición del Boletín Antinazi ${ }^{17}$ se enmarca en las actividades desarrolladas por el Comité Antinazi de los funcionarios del Instituto de Jubilaciones y Pensiones de Uruguay, agrupación surgida —según su manifiesto fundacional - en "solidaridad y ayuda con los pueblos en lucha contra el nazi-fascismo y sus aliados" y en "apoyo a la política de defensa y seguridad continentales". El Boletín, cuyo principal propósito era la lucha contra la "quinta columna" en la administración pública, tuvo como redactor responsable a Juvenal Ortiz Saralegui (1907-1959), poeta, crítico literario y periodista, mayormente conocido por su libro de poemas Palacio Salvo (1928) y por emprendimientos revisteriles como Vanguardia. Revista de Avance (1928) y Diario Mural de Ideas (1932). Representante del ala socialista en el Partido Colorado, cercano a figuras como Neruda, Blanca Luz Brum, Alberti y María Teresa León, fue un incansable defensor de la causa de la República Española, liderando numerosas acciones de ayuda a los intelectuales republicanos afectados por el franquismo. Desempeñó papeles destacados en la A.I.A.P.E., como ya se planteara el organismo más representativo del antifascismo en el campo cultural uruguayo. De hecho, los colaboradores del Boletín Antinazi, los temas, el tipo de acciones y la diagramación del mismo evidencian una notoria influencia del boletín de la Asociación, y como esta, el Comité Antinazi enfrentó conflictos en su interior por no disimular su simpatía hacia la Unión

17 Hemos consultado cuatro números consecutivos (1-4), conservados en la colección Juvenal Ortiz Saralegui del Archivo Literario de la Biblioteca Nacional. Aún no podemos precisar si el boletín tuvo más números. 
Soviética ${ }^{18}$.

Como en el caso de Mundial, aunque con recursos gráficos más limitados, la hibridación de imágenes y símbolos patrios con la cruzada antinazi constituye un recurso frecuente en esta publicación. A modo de ejemplo, en el número de agosto de 1944 ("edición extraordinaria del 25 de Agosto", conmemoración de la Independencia Nacional uruguaya), en la portada, debajo del marbete que identifica a la publicación, se extiende la imagen más icónica del héroe patrio José Gervasio Artigas ${ }^{19}$. De este modo, la lucha libertaria en la que se funda el discurso patriótico nacional se yuxtapone, a través de este montaje, con la lucha por la liberación de París de manos de los nazis.

Por otra parte, los textos del Boletín permiten observar la fusión del nazismo original (exógeno) con formas del fascismo palpitante en la realidad local, como las que se advertían en Mundial: versiones vernáculas (nacionales y regionales) del nazismo. En ese marco se insiste en los peligros del gobierno militar argentino. Los ataques al poder de Perón se realizan a través una transposición simbólica que retoma elementos de la historia regional bajo el gobierno de Juan Manuel de Rosas, representado por la historiografía liberal como el primer dictador populista de la Argentina independiente y proclive a ciertos usos sanguinarios del poder. Retomando ese imaginario, en el boletín, Montevideo vuelve a ser "la Nueva Troya", "ciudad de exiliados" (españoles, judíos y argentinos opositores): "Es que el rosismo está nuevamente en auge, en una trágica revisión histórica y enlazado por el nazi-fasci-falangismo de la época" (Boletín Antinazi 3, 9).

Pero la nota, a nuestro juicio, más singular del Boletín es la propuesta de acciones concretas para desenmascarar a los nazis en la oficina. Las instrucciones se resumen en: "iVigilar la acción nazista y los vende patria!” (Boletín antinazi 4, 1). En vista de que el país no contaba con un Servicio de Inteligencia, el contraespionaje era inexistente, de ahí que la publicación inste a los lectores-funcionarios del Estado a desempeñarse como cazadores de nazis. ¿Y cómo era posible reconocer a los

${ }^{18}$ Las afinidades ideológicas entre la AIAPE y el Boletín Antinazi son evidentes. Un ejemplo puede verse en el número de Antinazi que celebra la Liberación de París (3, 12 octubre 1944). Este se abre con una ilustración que representa el abrazo de un soldado del Maquis y un soldado de la Francia Libre. Al pie, la inscripción: "iiPor Francia!! Ayer Francia. Mañana España. Honor al soldado del mundo que libertará a los países del nazismo". Este fue el discurso de los sectores antifranquistas durante la Segunda Guerra Mundial. Su intervención en esta respondió a la unificación solidaria de los esfuerzos que luego, esperaban, habrían de volcarse a la liberación de España del franquismo.

19 Se trata de la obra pictórica "Artigas en la puerta de la Ciudadela" (1884) de Juan Manuel Blanes. 
infiltrados nazistas en el ámbito de las oficinas públicas? Aquí, algunas pistas:

Debemos vigilar dentro de la oficina a los que pudieran conspirar contra el rendimiento normal de la labor diaria, entorpeciéndola sin causa justificada y al sólo efecto de desprestigiar al Instituto, y por ende, al régimen.

Debemos vigilar al que sin razón baje su nivel de trabajo y pudiera ser agente para introducir una cuña entre el superior y sus subordinados (Boletín antinazi 4, 4).

Fue común, en la construcción del complot nazi en el Río de la Plata, la idea de que los conspiradores solían recurrir a los sobornos para corromper a la ciudadanía. Los postulados, como se comprende, son sumamente tendenciosos. De acuerdo con esta óptica, toda conducta desleal e inapropiada en la Institución sería interpretada como una acción de sabotaje y conduciría a un nazi criollo.

En el caso de Acción antinazi, se trata de una publicación del organismo del mismo nombre que trabajaba con gran cercanía con el Comité antinazi (de hecho, figuran ciertas referencias cruzadas en las publicaciones) ${ }^{20}$. La afinidad ideológica entre los boletines va más allá del combate contra la quinta columna y de la solidaridad con el frente aliado. Nacida en el ámbito fabril y liderada por activistas de izquierda (en especial, del Partido Comunista, como su secretario, el joven ingeniero José Luis Massera, que sería reconocido internacionalmente por sus investigaciones matemáticas), Acción antinazi publica textos de Ilya Ehrenburg, campañas de ayuda al Ejército Rojo y la organización de subcomités en las zonas rurales. Es, a todas luces, una publicación representativa de la retaguardia obrera en el Uruguay de la guerra.

En ese sentido, una sección de interés es la "Página de los talleres”, espacio en el que se expone cómo los obreros locales fabricaban diversos artefactos de utilidad para los ejércitos aliados. A diferencia del protagonismo del discurso sobre el complot nazi en otras publicaciones, en esta predomina la organización de acciones de ayuda material a los soldados que combaten al nazismo en Europa. La solidaridad con estos era entendida como el pago de una deuda, pues Acción antinazi concebía que la lucha en los frentes de batalla defendía no sólo la suerte de las naciones en guerra, sino también la libertad y seguridad del pueblo uruguayo. Su lema era "acrecentar y estimular la ayuda", lo que hace que - en su brevedad- el boletín se concentrara en datos concretos de las actividades de las

20 En la hemeroteca de la Biblioteca Nacional de Uruguay se conservan dos números del año 1944, correspondientes a julio y octubre, y uno de junio de 1946. 
comisiones, balances económicos, publicidad de festivales, campañas de insulina para los Aliados, etc.

Por último, sólo resta agregar que las dos publicaciones revisadas en este apartado fueron representativas, a su vez, del sector del antifascismo más alejado del liberalismo aliadófilo: el que reunió a los adherentes a la República Española y los comunistas (tras la entrada de la Unión Soviética en la contienda). Esta facción reclamó la continuidad de la guerra hasta la liberación de España, un acuerdo que nunca se cumplió y que fue determinante para la ruptura de la alianza y la polarización ideológica en la posguerra inmediata.

\section{Gauchos con esvástica: Mundo Libre, Estados Unidos y la amenaza peronista}

Presentada como una de las ediciones latinoamericanas de la Free World Magazine, editada en Estados Unidos durante la guerra ${ }^{21}$, Mundo Libre se publicó en Uruguay entre mayo de 1944 y junio de 1946. Tuvo un total de 25 números y se editó con una periodicidad mensual. Su director fue Hugo Fernández Artucio (1912-1974), figura estelar del antinazismo uruguayo y al que ya nos hemos referido anteriormente. Como en el caso de otros tantos intelectuales latinoamericanos, su compromiso antifascista lo transformó en un valioso candidato para el programa de intercambio cultural concebido en el marco de la Buena vecindad. Residió en Estados Unidos entre 1941-1943 y a su regreso, investido de la representación de las autoridades internaciones con sede en Nueva York, fundó la "Alianza Uruguaya por un Mundo Libre" y la revista, que también tuvo una editorial asociada, a cargo del filósofo y poeta Emilio Oribe ${ }^{22}$.

A diferencia de la estética lúgubre de Mundial o la austeridad de los boletines antinazis, Mundo Libre propone un diseño menos pesado y generosos toques de color, aspectos en los

${ }^{21}$ Free World (1941-1946) formaba parte de la Free World International Association, presidida por Eleanor Roosevelt y con gran actividad editorial en todo el continente.

${ }^{22}$ La labor de Oribe durante la guerra merecería un capítulo aparte. Su archivo, resguardado en la Biblioteca Nacional de Uruguay, permite reconstruir una incansable acción y producción textual en el ámbito de la diplomacia cultural de las naciones aliadas. Cercano al Embajador inglés Millington Drake y a pedido de este, Oribe realizó traducciones al español, audiciones radiales para la BBC y visitó universidades inglesas con el auspicio del British Council en la posguerra. Como Fernández Artucio, el escritor participó también como viajero intelectual de la Unión Panamericana en el año 1942. Quedan en su obra poética las huellas de la aliadofilia, como en "La campana de Ajax" (que canta el heroísmo de la armada británica, en particular al crucero "Ajax" que participó de la Batalla del Río de la Plata contra el acorazado alemán "Graf Spee") y el "Poema de Manhattan". 
que, en cierto modo, se podría leer la proximidad de la victoria aliada. El listado de colaboradores de la revista se componía de políticos y escritores rioplatenses y del ámbito internacional. Contaba con una sección literaria, que incluía básicamente colaboraciones de los poetas Emilio Oribe y Carlos Sabat Ercasty, y una de reseñas bibliográficas a cargo de Luis Gil Salguero.

Entre las líneas que identifican a la publicación se destacan la propaganda del panamericanismo, los grandes tópicos de la posguerra (reconstrucción, precariedad de las condiciones de vida, reorganización de Europa, el proceso a los criminales de guerra, funcionamiento de la O.N.U.) y en particular la exaltación del liderazgo norteamericano. En lo nacional y en coincidencia con la toma del poder por parte del Grupo de Oficiales Unidos (G.O.U.) en la Argentina, el imaginario que explota la revista es nuevamente el del peligro de la invasión de Uruguay por el nacionalsocialismo. En este sentido, se reproducen declaraciones de Cordell Hull, Secretario de Estado de Estados Unidos, en las que se señala a Buenos Aires como el "foco de infección del continente" y que

los nazis están por reanudar sus actividades desde la Argentina tan pronto termine la guerra actual. La prensa de Londres denuncia el día 17 que llegan a Barcelona de paso para Buenos Aires, funcionarios nazis. Preparan los caminos de jerarcas de primera línea. Los Amigos del Comité de Liberación Argentina dan un comunicado revelando que los viajeros ya están llegando a su destino (Mundo Libre 5 (1944), 23).

Así, al final de la guerra el enemigo oculto tomará la figura de Perón, líder del "nazismo argentino" o "gaucho-falangismo" (Mundo Libre 5 (1944), 23) 23, "resabio de las campañas hitleristas de Europa" que en "una ráfaga de locura totalitaria" podría lanzarse al imperialismo (Mundo Libre 7 (1944), 4) y anexar a su vecino oriental.

Las firmas de argentinos opositores al peronismo en las páginas Mundo Libre, como los socialistas Alfredo Palacios y Américo Ghioldi, alimentaron la vertiente antiperonista de la publicación uruguayo-norteamericana y ayudaron a conferir credibilidad a los datos sobre la carrera armamentista argentina y las actividades de tortura y represión de la "Gestapo porteña". Por otra parte, la intervención de estas figuras en Mundo Libre

${ }^{23}$ La apropiación de la imagen del gaucho para significar la criollización del nacionalsocialismo alemán fue frecuente en el periodo. Resulta interesante que un diario como Patria, identificado con el nacionalismo, publique una nota titulada "Ahora ven gauchos nazis...". El texto apunta contra los sectores pro-aliados a quienes acusa de accionar en base "al extranjerismo más descubierto e insensato" al punto de haber creado "en sus ya desquiciados cerebros, el fantasma del gaucho con una swástica (sic.)” (23 de enero 1942, 5). 
-algunos de ellos exiliados en Montevideo- conlleva otro interés, pues se trataba de colaboradores de la revista Argentina Libre $^{24}$. Esta presencia y trasiego de una orilla a otra, y de unas páginas a otras del movimiento antifascista rioplatense, abren un interesante campo en el estudio de las redes de revistas.

Con el estallido de un nuevo escándalo de espionaje (descubrimiento de comunicaciones entre supuestos espías uruguayos y argentinos) en febrero de 1945, se estimó que la conspiración que había salido a la luz al inicio de la guerra había continuado operando gracias a la estructura financiera de la colonia alemana en Uruguay. Al llamado a estar alertas se sumó entonces y por indicación estadounidense el proceder con un boicot económico a las empresas sospechosas de connivencia con el nazismo. Por su parte, Mundo Libre, ante la amenaza que representaba el gobierno argentino en la región, propuso que era imperioso armarse y se embarcó en una campaña por la defensa nacional, que incluyó una gira por el interior del país.

Asimismo, el esfuerzo de la revista por mantener vivo el imaginario del nazismo fue considerable. Agustín Brena afirmaba en una nota: "el enemigo anda entre nosotros como león rugiente", argumentando por qué debería mantenerse en pie la Comisión Investigadora de Actividades Antinacionales (Mundo Libre 20 (1946), 12). En febrero de ese año, la redacción sufrió un atentado con explosivos, que fue presentado por la revista como un reconocimiento de su actuación al servicio de la democracia. Esto sucedía a escasos días de la victoria del general Perón en las elecciones. En su número siguiente, la publicación tituló: "Argentina tiene su nuevo Fuehrer (sic)" $\left(n^{\circ} 23,1946\right)$ e incluyó una fotografía del nuevo presidente en uniforme militar y una gestualidad evocadora de las figuras más reconocidas del totalitarismo.

La publicación de Mundo Libre se extendió por poco tiempo más, hasta junio de 1946. Como instrumento para la intervención norteamericana en la región, la revista colaboró tenazmente con la condena al peronismo y a la colonia alemana, y la promoción de la militarización de Uruguay de acuerdo con las lógicas del sistema panamericano, un orden que finalmente triunfó y sentó las bases de la cooperación militar desarrollada durante las dictaduras del Cono Sur.

\section{Colofón}

La constelación de publicaciones que hemos revisado integra la copiosa literatura que registra la recepción del complot nazi en

24 Esta publicación había sido clausurada por el gobierno militar en 1944. En febrero de 1945, el grupo retomó el proyecto, pero bajo otro título: Antinazi (Bisso 2009). 
América Latina. Según se ha propuesto en el trabajo, la traducción cultural e hibridación del mito de la conspiración nazi-nacionalista como enemigo de la nación uruguaya tomaron cuerpo a través de diversos procedimientos figurativos. Lo más destacado de ese catálogo se resume, por un lado, en la representación de agentes extranjeros y nacionales del nazismo exógeno, de acuerdo con el esquema del enemigo interno, y por otro, en imágenes que mantienen algunos rasgos de esa figuración, pero acentúan las notas de un nazismo criollo ("gaucho"), coincidentes con el ascenso de Perón en Argentina. En todos los casos se proponía una caracterización del enemigo sumamente estereotipada, vaga o difusa en su amplitud, lo que hacía difícil la identificación del mismo y reforzaba las paranoias o psicologías de la sospecha. De este modo, las revistas funcionaron como medios del alarmismo, instando a los lectores a mantenerse alertas para identificar y derrocar a un enemigo que operaba en las sombras. Fueron, a un mismo tiempo, formas de resistencia al peligro y difusoras del miedo.

Por otra parte, según se ha visto, el papel de los intelectuales en esta guerra de las representaciones tuvo una gran relevancia, pues la producción del "gran miedo", como ficción de control protagónica, resultó decisiva para asegurar la unidad del frente antifascista y desarrollar la campaña antigermana que sirvió principalmente a los intereses norteamericanos. Sin duda, la credibilidad que los escritores estudiados forjaron a partir de una militancia antifascista durante la década del treinta ayudó a su construcción como voceros de la amenaza nazi en el ámbito local. De este modo, Francisco Espínola, Juvenal Ortiz Saralegui, Hugo Fernández Artucio y sus revistas colaboraron con el proceso de apropiación e intervención político-cultural que las ficciones mundiales operaron en Uruguay durante la guerra.

\section{Bibliografía}

Alpini, Alfredo. La derecha en Uruguay en la era de los fascismos (1930-1940). Montevideo, Fundación de Cultura Universitaria, 2015.

Bisso, Andrés. "Argentina libre y Antinazi: dos revistas en torno de una propuesta políticocultural”. Temas de Nuestra América, $\mathrm{n}^{\mathrm{O}} 25$, vol. 47, 2009, pp. 63-84.

Brena, Tomás y Julio Iturbide. Alta traición en el Uruguay. José Serrato (pról.), Montevideo, A. B. C., 1940.

Camou, María M. "El nacional-socialismo en Uruguay, 19331938”. Cuadernos del CLAEH, n 38, 1986, pp. 67-83. 
Cerrano, Carolina y Fernando López D’ Alessandro. “Las Fuerzas Armadas uruguayas durante la Segunda Guerra y el advenimiento del peronismo (1939-1945)". Historia, $\mathrm{n}^{\circ} 51,2018$, pp. 11-29.

Crawford, Neta C. "The Passion of World Politics: Propositions on Emotion and Emotional Relationships". International Security, $\mathrm{n}^{\circ}$ 4, vol. 24, 2000, pp. 116-156.

Degiovanni, Fernando. Vernacular Latin Americanisms: War, the Market, and the Making of a Discipline. Pittsburgh, Pittsburgh University Press, 2019.

Delumeau, Jean. La peur en Occident (XIVe-XVIIIe Siècles): Une cité assiégée. Paris, Fayard, 1978.

Derrida, Jacques. Políticas de la amistad seguido de El oúdo de Heidegger. Patricio Peñalver y Francisco Vidarte (trads.), Madrid, Trotta, 1998.

Eco, Umberto. Construir al enemigo y otros escritos. Elena Lozano (trad.), Barcelona, Lumen, 2012.

Espagne, Michel. Les Transferts culturels franco-allemands. Paris, Presses Universitaires de France, 1999.

Espínola, Francisco. "El Paco" en París (recopilación de artículos de Francisco Espínola a El País entre el 25 de julio y el 8 de setiembre de 1959). Assia Viera-Gómez (pról.), París, Tiempo Uruguayo, 1984.

Fernández Artucio, Hugo. Nazis en el Uruguay. Vicente Basso Maglio y José Cardoso (pról.), Montevideo, Talleres Gráficos Sur, 1940.

Friedman, Max Paul. Nazis y buenos vecinos: La campaña de EE UU contra los alemanes de América Latina durante la II Guerra. Jaime Blasco (trad.), Madrid, Antonio Machado, 2018.

Gran Logia de la Masonería del Uruguay. "Hermano Francisco 'Paco' Espínola".

http://www.masoneriadeluruguay.org/?q=node/165 Fecha de consulta: 27/11/2019.

Louis, Annick. Borges y el fascismo. Bruselas, Peter Lang, 2007.

Maggi, Carlos. Paco Espínola: vida y obra. Capítulo oriental: la historia de la literatura uruguaya $\mathrm{n}^{\circ}$ 26, Buenos Aires, CEDAL, 1968. 
Mutti, Julio. Nazis en las sombras. Madrid, Nowtilus, 2015.

Navascués, Javier. "El tópico de la invasión: de Bioy Casares a Ricardo Piglia". La literatura argentina del siglo $X X$ : un recuento. Relecturas de la Argentina del siglo XX ficcionalizada. Mirjana Polic, Gordana Matić y Antonio Huertas Morales (eds.), Zagreb, Universidad de Zagreb, 2015, pp. 187-197.

Richards, Thomas. The Imperial Archive: Knowledge and the Fantasy of Empire. New York, Verso, 1993.

Rocca, Pablo. "Advertencia". Primera recepción crítica de Francisco Espínola (1927-1939) (Homenaje en el centenario). Montevideo, Universidad de la República/Facultad de Humanidades y Ciencias de la Educación, 2002, pp. 5-11.

Rodríguez Ayçaguer, Ana María. Un pequeño lugar bajo el sol. Mussolini, la conquista de Etiopía y la diplomacia uruguaya. 1935-1938. Montevideo, Banda Oriental, 2009.

Tricánico, Santiago. El nazismo en el Río de la Plata. Montevideo, Rumbo, 2012.

Viu, Antonia. "Lloremos y traduzcamos. La Segunda Guerra Mundial y la Cooperación Intelectual desde Babel. Revista de revistas (1939-1940)". Homo dolens. Cartografías del dolor: sentidos, experiencias, registros. Rafael Gaune y Claudio Rolle (eds), Santiago de Chile, Fondo de Cultura Económica, 2018, pp. 418-434.

\section{Archivo}

Archivo Literario de la Biblioteca Nacional de Uruguay. Colecciones Juvenal Ortiz Saralegui y Emilio Oribe.

\section{Revistas}

Acción Antinazi

AIAPE: Por la defensa de la cultura

Boletín Antinazi

Marcha

Mundial

Mundo Libre

\section{Diarios}

El País

Libertad

Patria 